\title{
Australia's National Electricity Market after twenty years
}

\author{
Alan Rai and Tim Nelson* \\ Level 5, 201 Elizabeth Street \\ Sydney, NSW, 2000
}

October 2019

The Hilmer reforms introduced competition into electricity generation and retailing, with the natural monopoly elements economically regulated and structurally separated. For the first decade post reform, these reforms served consumers well. However, three key issues emerged from the mid-2000s: (i) a significant and largely unnecessary rise in network expenditures; (ii) emissions policy discontinuity; and (iii) more recently, a large increase in wholesale prices from the confluence of rising fuel prices and unexpected and sudden exits of generators. The consequence was a doubling in retail prices. Also, deficiencies in cost recovery mechanisms have meant price increases have disproportionately affected low-income customers. We propose three key reforms as rectification: (i) integrating emissions reduction and energy policies; (ii) measures to boost network capacity utilisation; and (iii) improvements to cost recovery mechanisms.

Keywords: electricity markets; energy policy; microeconomic reform JEL Codes: D04; D20; D31; D40; O13; Q40; Q41; Q42; Q48; Q50; Q58

\section{Introduction}

Prior to the 1990s Hilmer microeconomic reforms, the east-coast Australian electricity industry's functions - generation, transmission and distribution, and retail supply - were verticallyintegrated within government-owned state electricity commissions. Following the reforms, the

\footnotetext{
- Alan Rai is a Senior Economist at the Australian Energy Market Commission (AEMC), a Senior Fellow at Macquarie University, and an Industry Fellow at the University of Technology Sydney (UTS). Tim Nelson is Executive General Manager - Economic Analysis at the AEMC, and an Associate Professor at Griffith University. The authors thank Sarah Panizza and Jessie Foran, both at the AEMC for their assistance, and the comments from two anonymous referees and the editor (Ross Williams). All views, errors and omissions are entirely the responsibility of the authors, not the AEMC, Griffith, Macquarie, or UTS. Correspondence to alan.rai@uts.edu.au
} 
competitive components (electricity generation and retailing) were separated from those with monopoly characteristics (transmission and distribution).

For most of the post-reform period, these reforms served electricity consumers well, with lower prices, improved reliability and increasing product innovation, compared to the pre-1990s experience. However, three key problems emerged from the mid-2000s:

1. A sustained rise in distribution network expenditures. This was due to the combination of: overestimated demand forecasts; an excessive tightening in network reliability standards; and Global Financial Crisis-induced high regulated rates of return.

2. A lack of clarity and policy continuity in relation to emissions reduction objectives and policy mechanisms; and a lack of integration between energy and emissions reduction mechanisms. Gas-fired generation had been viewed as the 'transitional fuel' for the NEM's decarbonisation (Nelson et al., 2010). Policy focused instead, however, on production subsidies for renewable energy.

3. The lack of policy continuity, and participants' exposure to rising, export-parity induced, coal and gas prices, increased the costs of existing and new-entrant dispatchable plant. Over time this has led to economic pressure on incumbent thermal plant and eventually the unexpected and sudden exits of large-scale generators. The combination of these events meant the market was unable to respond in a timely fashion to arrest the significant wholesale price increases that resulted from the exit of large-scale plant.

The consequence of these three forces was an approximate doubling in residential electricity prices over the past decade. This has been compounded by the regressive nature of residential electricity price rises, reflecting inadequacies, inefficiencies and inequities in existing redistribution and cost-recovery mechanisms. 
A key objective of the 1990s reforms of the electricity industry was enhancing the productivity and efficiency of the industry. Therefore, the trend in electricity prices is used to contextualise our discussion of the electricity industry reforms. The focus of this paper is on residential prices and potential further reforms to address the negative consequences of the three factors noted above.

The paper is structured as follows. Section 2 discusses the origins of reform in the electricity industry, while Section 3 discusses the Hilmer reforms of the early 1990s. The post-reform period can be divided into two broad eras: 1998-2008, and post-2008, which are discussed in sections 4 and 5 respectively. Section 6 discusses the regressive nature of recent price increases, and Section 7 concludes by discussing the key reforms that are required going forward.

\section{The origins of reform $-\mathbf{1 9 5 5}$ to $\mathbf{1 9 9 3}$}

Australia's post-World War II era was marked by rapid economic industrialisation. The electricity industry was both a part of, and a contributor to, this industrialisation. The industrialisation process did not commence till around a decade after World War II. This was due to world-wide and domestic bottlenecks in the expertise required to build and install new generating capacity during and immediately following the War. This led to serious power supply shortages across Australia, exacerbated by prolonged and severe droughts and coal shortages (Brady, 1997).

However, from the mid-1950s, the amount of installed generation capacity increased ten-fold, from around $3 \mathrm{GW}$ in 1955 to $30 \mathrm{GW}$ to the mid-1990s (Figure 1). To date, this has been the most rapid growth of capacity the electricity industry has ever seen. The industry expanded through the utilisation of centralised generation that produced large volumes of energy transported over long distances through an interconnected transmission and distribution system.

[insert Figure 1 here] 
From a pricing perspective, there are two distinct periods worth noting. The first period is the 1955-1980 period. During this period, real electricity prices fell significantly as economies of scale were utilised from the construction of large thermal power stations utilising relatively lowcost Australian coal and gas. Between 1955 and 1980, real residential electricity prices in NSW fell from $\$ 375 / \mathrm{MWh}$ to $\$ 164 / \mathrm{MWh}$, a decline of 56 per cent. Over the same period, residential prices in Queensland fell from \$350/MWh to \$210/MWh, a decline of 43 per cent (Figure 2). ${ }^{1}$

The second period evident from Figure 2 starts from the early 1980s. Between 1982 and 1986, there were material price increases (around 20 per cent in both NSW and Queensland) from the increased investment in capacity by state-owned electricity commissions with costs explicitly passed through to consumers. ${ }^{2}$

[insert Figure 2 here]

These price increases were all the more concerning given the stagflationary outcomes across the economy. During the mid-' 80 s, annual inflation was around 9-10 per cent. This meant that, in nominal terms (i.e. using the cost of living at that time), residential electricity prices rose by around 60 per cent, in just a four-year period between 1982 and 1986.

\section{The electricity sector reforms of the $1990 \mathrm{~s}$}

The Hilmer reforms sought to allocate the risks of investment in generation and retailing to market participants, and away from consumes and taxpayers, as a means to achieving allocative efficiency and greater productivity. This provides context for considering our recommendations in section 7 .

\footnotetext{
${ }^{1}$ Unless otherwise noted, all dollar amounts in this paper are expressed in constant 2018-year Australian dollar prices.

${ }^{2}$ There are also likely to have been subsidies incurred through the use of state government balance sheets.
} 
Energy sector reform was driven by the Australian States - starting with Victoria and New South Wales (NSW) - rather than by the Commonwealth ${ }^{3}$. This reflects the fact that energy policy has been, and largely remains, the domain of State Governments, since vertically-integrated monopoly electricity commissions were developed, owned and operated by State Governments, rather than the Commonwealth (Simshauser, 2019). The reforms in each State had the following common elements (Chester, 2006; Simshauser, 2019):

- Electricity commissions were 'corporatised' (i.e. commercialised entities incorporated under the Australian Corporations Law) and vertically restructured into three business segments: generation, transmission, and distribution/retail supply, within existing state boundaries. This was followed, after a period of time, with structural separation of retail supply from electricity distribution.

- Each business segment was treated on an arms-length, competitively-neutral basis, which reduced the benefit (such as reduced borrowing rates from implicit or explicit Government guarantees on funds borrowed) arising from raising capital. This process was important in providing a level playing field between State-owned and, as emerged over time, the entry of privately-owned electricity businesses.

- Trials of power markets to demonstrate the feasibility of competition in the generation sector. For example, in 1991 the Electricity Commission of NSW - which was corporatised, restructured and renamed to Pacific Power - established an internal power market (ELEX), and a similar market (VicPool II) was established in Victoria in 1992.

- Use of 'vesting' contracts for the sale of electricity to retailers from generators to minimise the risks to generators and consumers in the transition to a competitive market

3 Booth (2000) notes the first attempt at reform was in the mid-1980s by Paul Keating, who at that time was the Commonwealth Treasurer. Keating offered to use Commonwealth taxpayer funds to finance increased interconnection between NSW and Victoria, an offer subsequently rejected by both of those States. 
- Gradual unwinding of cross-subsidies between consumer groups (for example, from industrial and commercial to residential groups).

- Establishment of independent regulatory agencies responsible for the economic regulation of the sector and in particular the economic regulation of the transmission and distribution network businesses.

The market trials in Victoria and NSW used the England and Wales gross pool as a design template. ${ }^{4}$ These trials provided evidence, and thereby confidence, that Industry Commission (1991)'s recommendations could be successfully applied to the electricity industry. These experiences also informed and shaped the national microeconomic reform program in the areas of market design, network access regimes, industry restructuring, and the development of regulatory frameworks. This provided a level of consistency across the jurisdictions - and laid the foundation for the transition to the NEM - whilst enabling each jurisdiction to tailor the reform program to account for local issues (such as legacy power supply contracts with industrial customers and community service obligations).

There was a staged transition to an inter-jurisdictional east-coast NEM from the trial markets in Victoria and NSW. It started with the establishment of live markets in Victoria (VicPool III) and NSW (NSW State Electricity Market) in 1993 and 1996, respectively. These two markets were joined in 1997 (called 'NEM1'). South Australia participated as a separate trader in NEM1 and then joined the NEM from day one (13 December 1998). Queensland also joined the NEM on day one, but operated as a separate regional pool until interconnection with NSW in 2001. Tasmania joined the NEM in 2005.

\section{1998 to 2008 - a decade of success}

\footnotetext{
4 A key difference between the England \& Wales design, and the Victorian and NSW market trials, was that the former had capacity payments, whereas the latter did not.
} 
The NEM formed part of a world-wide electricity industry microeconomic reform experiment, which commenced in Chile in 1982 (Pollitt, 2004; Simshauser, 2019). The overall aim of the NEM was, and is, to provide a reliable, secure energy supply at the best possible price for consumers. This was to be obtained by designing and enabling competitive markets where competition was feasible, coupled with robust and resilient regulatory frameworks to complement competition (and substitute for it where competition was not efficient).

By introducing competition, operational and investment decisions would be decentralised away from central planners (i.e. governments and regulators) to commercial parties. The NEM was founded on the following key economic principles (Chester, 2006; Simshauser, 2019):

- Appropriate risk allocation: in the NEM, risk allocation and the accountability for investment and operational decisions rests by and large with market participants, as it is these parties who have the best information, expertise and incentive to manage such risks. Prior to the NEM, investment decisions were centrally directed, prices did not reflect efficient costs, and risks associated with the (low) efficiency of the sector were therefore entirely borne by consumers and taxpayers.

- Promoting competition

- Flexibility and resilience of the regulatory and market frameworks: the establishment of the NEM was, and is, about allowing market and regulatory frameworks to evolve with new technologies and consumer expectations..

- A mechanism to reduce production costs 
Simshauser (2019), p.1 argues that, by virtually every metric, the NEM has been a "resounding success" and a "marvel of microeconomic reform", at least over the period to June 2016. A vast oversupply of generation plant was cleared, unit costs plunged, plant availability rates reached world class levels, requisite new investment flowed when required, investment risks were borne by capital markets rather than captive consumers, and reliability of supply had been maintained, with few exceptions, due to a very high market price cap (at A\$14,500/MWh for 2018/19), amongst the highest in the world.

The NEM inherited a high-quality and oversupplied stock of monopoly-built utility-scale plant at inception. Simshauser (2019) estimates that, at the time of NEM commencement, excess capacity was almost 10 per cent, due solely to significant excess supply of high-capacity factor plant (around 4100MW, or 20 per cent, of total baseload capacity). ${ }^{5}$

This excess supply kept wholesale spot prices generally in a relatively tight range of $\$ 40$ \$60/MWh (inflation-adjusted) over the 1999-2008 period (Figure 3), though prices spiked in 2007-2008 due to Australia's east coast millennial drought. ${ }^{6}$ Quiescent prices over the 1999-2008 period also reflected timely new-entrant generation. Plant entry during the early-to-mid 2000s more than matched the increase in electricity demand during that period, resulting in wholesale prices that were flat or falling during the first half of the 2000s. Between 2000 and 2005, annual consumption increased by 12 per cent, yet prices fell by 15 per cent. The sharp run-up in wholesale prices from 2016 onward is discussed in Section 5.

5 In contrast, Simshauser (2019) estimates that there was a deficit of almost 20 per cent (around 1,600MW) of peaking capacity, compared to the optimal amount of peaking capacity required in the NEM.

6 In addition to adverse effects on hydro plant, the drought forced some coal-fired generators to mothball units due to cooling water shortages, with urban drinking water being prioritised from affected dams (Simshauser, 2019). 
Similarly, the plant entry during 2007 and 2008 helped limit the drought-induced increases in wholesale prices, and countered the price pressures that may have otherwise occurred from the (modest) growth in demand. Between 2008 and 2010, annual consumption increased 1 per cent. Over the decade to 2009, more than 6,000 MW of gas-fired plant (both intermediate and peaking) entered the NEM. More than half of this (totalling almost 3,600 MW) entered in 2008 and 2009 alone, in response to policy signals ${ }^{7}$ and the drought-induced price spikes of 2007-2008. This investment at-scale, delivered in a timely fashion and in sufficient quantity, also helped keep a lid on wholesale prices.

[insert Figure 3 here]

Generally quiescent wholesale prices, coupled with flat network prices, meant end-consumer electricity prices were broadly unchanged; during the decade to end-2008, real residential prices rose just 6 per cent (or 0.6 per cent per year) and 8 per cent (or 0.8 per cent per year) in NSW and Queensland, respectively (Figure 2). Modest end-consumer electricity prices are one indicator that the NEM worked well during the 1998-2008 period. Another indicator is the timely entry of new generation plant, especially those plants (i.e. peaking plant) underweight at the time of NEM commencement, in response to price signals.

Flat consumer prices needs to be put in the context of significant drivers for increased prices: one of the worst droughts in Australia's history, combined with steadily increasing demand, and the removal of subsidies paid by large electricity customers to residential customers. Competition drove lower prices despite the significant upward pressure on costs. ${ }^{8}$

[insert Figure 4 here]

7 These policy signals were the Queensland Gas Scheme (QGS) and the NSW Greenhouse Gas Abatement Scheme. The QGS commenced in January 2005, and required electricity retailers to source 13 percent (later increased to 18\%) of their Queensland electricity from gas-fired generation. In the first year of the scheme, over $1600 \mathrm{MW}$ of generation capacity (across ten gas-fired power stations) was reported to have been accredited (Queensland Government, 2007).

8 Furthermore, the privatisations of previously government-owned entities provided significant relief to government finances and budgets, enabling governments to redirect their scarce resources towards other areas, such as education, health and transport. This was especially true for government-owned businesses in NSW and Victoria, with concerns about the high and rising debts of these businesses prior to their privatisations (NSW Treasury, 1997). 


\section{2009-2019: three key drivers of the doubling in real prices}

In contrast to the first decade following the NEM's commencement, prices climbed sharply in the second decade. Between July 2008 and July 2014, real residential prices in NSW rose by 96 per cent (from $\$ 170 / \mathrm{MWh}$ to $\$ 334 / \mathrm{MWh}$ ). In Queensland, prices rose by 118 per cent (from $\$ 174 / \mathrm{MWh}$ to $\$ 379 / \mathrm{MWh}$ ) over the same period (Figure 2). Since then, prices have moderated, with NSW and Queensland residential prices falling by 2 per cent and 11 per cent, respectively, due to a drop in network tariffs. Strikingly, prices in 2018 were at five-decade highs, and on par with prices last observed in the late 1950s. The broad consensus amongst a range of energy policy institutions and academics is that three principal factors contributed to this increase in electricity prices (ACCC 2018; AEMC 2018; Simshauser 2019):

1. A sustained rise in network expenditures, particularly at the distribution level. Across the NEM, real residential prices rose 85 per cent (or \$151/MWh) between July 2008 and 2018 (Figure 5). Of this, the networks component comprised two-fifths (or \$60/MWh).

2. A lack of certainty around emissions reduction targets and trajectories, which, in combination with high and rising gas prices, has raised barriers to entry, especially for gas-fired plant. Furthermore, the emissions reduction mechanisms that exist - such as the Renewable Energy Target and various government schemes - are designed solely for zero-emissions technologies. This lack of technology neutrality has precluded cheaper forms of emissions abatement, leading to higher wholesale prices as compared to a technology-neutral mechanism. Furthermore, production subsidies have not provided an economic signal for efficient exit of plant, and have in turn led to disorderly exit of plant and raised the cost of the NEM's transition to a lower-carbon world (Nelson et al., 2017). Of the 85 per cent increase in residential prices between 2008 and 2018, environmental costs contributed around one-eighth (or \$20/MWh). 
3. Rising wholesale prices, which contributed around three-tenths (or $\$ 44 / \mathrm{MWh}$ ) of the 85 per cent increase in NEM-wide residential prices. A combination of policy discontinuity and rising fuel costs resulted in a lack of entry of new dispatchable plant, especially gas-fired plant, despite rising wholesale prices in 2016 and 2017 (Figure 5).

[insert Figure 5 here]

\subsection{Increase in network prices}

Between 2006 and 2015, there was a near-tripling in the size of the regulatory asset base (RAB) of the combined (transmission and distribution) electricity network businesses in the NEM (Simshauser, 2019). The increase in RABs was driven primarily at the distribution network level, where RABs increased from $\$ 40$ billion in 2006 to $\$ 70$ billion in 2015 (Figure 6). Distribution networks' annual revenues also increased, from $\$ 7$ billion in 2006 to $\$ 12.5$ billion in 2015 . The increase in distribution RABs and revenues was due to a combination of (Simshauser, 2019):

- An excessive tightening in network reliability and bushfire standards in NSW and Queensland, following widespread network outages in parts of those states in 2004 and 2005, without due regard for consumers' willingness to pay for marginal increases in reliability. While network reliability standards were subsequently loosened, the increases in $\mathrm{RABs}$ - and accompanying increase in network revenues and prices - were locked in.

- Overestimated forecasts of peak demand - there was first a slowing in peak demand growth in the late 2000s, with demand then plateauing in 2009/10 (Figure 3). Demand then steadily declined over the early-to-mid 2010s. Overestimated demand meant investments were made, and costs incurred, that are likely to be unnecessary with the benefit of hindsight. That said, localised peak demand growth in some areas (due to the absence of cost reflective tariffs and air conditioning penetration growth) continued to contribute to network costs. 
- The rollout of mandatory smart meters from 2009 was a major driver of network cost increases in Victoria.

- These large investments occurred during a period of financial market instability (i.e. the Global Financial Crisis), which increased financing costs and hence increased regulated rates of return to historically high levels.

[insert Figure 6 here]

The increases in RABs across the NEM were not uniform. In particular, the RABs in Queensland, NSW and to a lesser extent Tasmania grew at a much greater rate than in South Australia and Victoria. Some of this difference has been attributed to the fact that Victorian and South Australian network businesses are privately-owned, whereas NSW and Queensland businesses were, at that time, state government-owned (Mountain and Littlechild, 2010).

The increase in distribution networks' RABs and revenues led to a surge in network prices, from $\$ 36.8 / \mathrm{MWh}$ in 2006 to $\$ 68.4 / \mathrm{MWh}$ in 2015 , an increase of 85 per cent. The increase in network prices was compounded by a flattening in electricity consumption, which has meant the network price, on a per-MWh basis, has increased at a faster rate than network revenues (Figure 6). ${ }^{9}$

\subsection{Lack of integration between emissions and energy policies}

9 It is worth noting that the network component of the residential tariff in Figure 5 differs from the network amount in Figure 6 in two ways. First, the values in Figure 6 relate to the average network cost/price for all customer segments (not just residential). Second, the values in Figure 6 are for the distribution network component only, whereas the values in Figure 5 are for both transmission and distribution. 
The emissions reduction mechanisms that currently exist in Australia, such as the Renewable Energy Target (RET) and various state government schemes, are production subsidies designed solely for zero-emissions technologies. Subsidising certain forms of generation over directly pricing the externality of greenhouse gas emissions creates technology non-neutrality. This has had two effects. First, alternative and potentially cheaper forms of emissions abatement have been precluded, thereby leading to higher wholesale prices than would have been expected to occur under a technology-neutral mechanism like an emissions intensity scheme. Emissions abatement from reducing the emissions intensity of existing plant has also been precluded. Second, the link between financial risk management and the physical needs of the electricity system has been broken (Nelson et al, 2019; AEMC, 2016; Simshauser, 2014).

The incentive under the RET has been to maximise generation output, irrespective of the prevailing wholesale electricity price. In contrast, other generators have remained incentivised to respond to wholesale prices, due to their reliance on wholesale price signals rather than on subsidies. This lack of technology neutrality has occurred at the utility-scale - under the Largescale Renewable Energy Target $\left(\operatorname{LRET}^{10}\right)$ - and at the small-scale, under the Small-scale Renewable Energy Scheme (SRES). ${ }^{11}$

Subsidies for small-scale generation were enhanced by state government-mandated minimum feed-in tariffs (FiTs) for solar PV systems.

\footnotetext{
10 The renewable energy target was set at 9.5 terawatt hours (TWh) by 2010. In January 2011, a target of 41 TWh by 2020 was set, but in June 2015 was subsequently revised down to 33 TWh by 2020 . This annual amount remains unchanged through to 2030, which is when the LRET is scheduled to end (CER, 2018).

${ }^{11}$ The SRES provides a subsidy through to 2030. Unlike the LRET, there is no annual target under the SRES (i.e. it is an uncapped scheme) as the SRES is based on maintaining a constant subsidy at or around \$40/MWh (CER, 2018).
} 
The consequence of the use of these types of policy mechanisms has been to create a disorderly transition whereby "firm dispatchable" plant has been rapidly retired prior to new equivalent plant being in place. The resulting tightening in the supply-demand balance has put significant upward pressure on wholesale prices. Between June 2012 and June 2017, 4,255 MW of coal-fired plant exited the NEM (Figure 4). All these plant exited relatively quickly - the weighted-average notice period was just 2.9 months, with the highest notice period being 6.9 months for the 540 MW Northern power station in South Australia (Simshauser, 2019). The large amount of exits, combined with notice periods that were far lower than the time needed for new dispatchable plant to enter, contributed to spot prices reaching multi-year highs.

\subsection{Higher wholesale prices}

As a consequence of a "disorderly transition" caused by policy discontinuity and reliance on production subsidies in the form of renewable electricity certificates (rather than a broad economy wide externality price), between January 2016 and December 2018 wholesale spot prices more than doubled in NSW, South Australia and Victoria, with Victoria recording a 189 per cent increase. ${ }^{12}$ Across these four States, spot prices rose 95 per cent, from $\$ 44.8 / \mathrm{MWh}$ to \$87.6/MWh, between 2015/16 and 2017/18 (Figure 3). ${ }^{13}$

The increase in wholesale prices contributed to the increase in residential electricity prices between 2016 and 2018, more than offsetting the decline in network prices over this period. In addition to the unexpected and quick exit of large-scale generators, the increase in wholesale prices has also been due to rising coal and gas prices. Between 2015 and 2018, coal prices rose 74 per cent, from $\$ 38 / \mathrm{MWh}$ to $\$ 66 / \mathrm{MWh}$ equivalent, and gas prices rose 115 per cent, from \$54/MWh to $\$ 117 / \mathrm{MWh}$ equivalent (

\footnotetext{
12 These price effects reflect the longer-term, dynamic effects of adding more renewables into the system, namely the exit of incumbent thermal plant in response to the entry of new generators, and not just the short-term 'merit-order' price effect. Nelson et al, (2012) note that these dynamic effects have swamped the merit-order effect in the NEM.

13 The increase in Queensland spot prices (32 per cent) was less, due partly to the effect of the Queensland Government's direction to Stanwell Corporation in June 2017 to "alter its bidding strategies to place downward pressure on wholesale prices" (Queensland Government, 2017).
} 
Figure 7).

[insert Figure 7 here]

\section{The regressive nature of price increases}

As a proportion of income, prices have risen the most for the most financially vulnerable. Lowincome households on the median retail tariff spent almost 7 per cent of their income on electricity during 2017-18, compared to $4 \frac{1}{2}$ per cent in 2013-14. In contrast, medium-income households on the same tariff spent $3 \frac{1}{2}$ per cent of their income on electricity during $2017-18$, compared to 1.3 per cent in 2013-14 (Figure 8). The evidence in Figure 8 implies that the increase in electricity prices has disproportionately impacted on lower-income groups. ${ }^{14}$

The values in Figure 8 assume the same amount of electricity consumption $(5,689$ KWh p.a.) for low- and middle-income households. Low- and medium-income households are also assumed to be on the same offer. ${ }^{15}$ While both assumptions may not always hold in practice, the virtue of these assumptions is that potential differences in electricity bills due to consumption differences, and/or differences in the average retail tariff each household segment is paying, are controlled for, thereby enabling a direct examination of prices paid by household-income segment.

ACCC (2018) found that electricity consumption is negatively correlated with measures of financial vulnerability; that is, more financially vulnerable households tended to have lower consumption than less vulnerable households. ${ }^{16}$ In contrast, Simshauser and Whish-Wilson (2017) found consumption to be positively correlated with measures of vulnerability. The constant-consumption assumption controls for these inconsistent findings.

\footnotetext{
${ }^{14}$ In the context of modelling the economy-wide impact of a $\mathrm{CO}_{2}$-e emissions reduction mechanism, Meagher et al. (2014) argue the impact of this mechanism on electricity prices paid by all electricity consumers - households and businesses - may not be regressive. However, these findings may be sensitive to the formulation of the general equilibrium model.

15 This is the median of all market offers, in those years and regions where retail prices were deregulated, and the standing offer in those years and regions where prices were regulated. AER (2018a) details the methodology used.

${ }^{16}$ Annual average consumption of non-vulnerable households $(5,709 \mathrm{KWh})$ was found to be higher than for households identified as vulnerable $(5,105 \mathrm{KWh})$. Middle-income households with two dependents $(6,540 \mathrm{KWh})$ and households with a mortgage $(5,978 \mathrm{KWh})$ were the two exceptions to this. See Figure 15.3 of ACCC (2018).
} 
Based on the evidence in Figure 8, we contend that, ceteris paribus, there are inadequacies and deficiencies in existing cost-recovery mechanisms. These mechanisms are:

- recovery of transmission and distribution network costs, and

- cost recovery mechanisms for government-mandated subsidies.

[insert Figure 9 here]

As noted elsewhere (for example, Sood (2014) and Simshauser \& Downer (2016)), the structure of existing network tariffs recover more of network costs via the volumetric (i.e. per-kWh) component vis-à-vis the other tariff components, in particular, the 'demand' charge or per-kW component. In contrast, network investment costs are largely fixed and sunk. By setting volumetric charges above their efficient levels, thereby setting fixed charges below their efficient levels, more of the costs of network provision are allocated to higher-consumption customers and to those who are unable to reduce their grid-sourced electricity consumption (Simshauser, 2016). This approach is regressive in nature when grid-sourced consumption is negatively correlated with income. As home-owners have been the heaviest adopters of rooftop PV, this has reduced their grid-sourced consumption, and therefore reduced their contribution to network costs. This meant low-income and rental households, who were unable to afford PV systems, had to bear an increasing share of network costs (Simshauser, 2016; Simshauser, 2014).

In relation to government-mandated subsidies, all Australian states have had some form of government-mandated FiT, with the largest being the "premium" schemes of $\$ 440-\$ 600 / \mathrm{MWh}$ in NSW and Victoria during the 2010s. The economic value of this roof-top PV output, which equates to the value of the forgone grid-sourced power, was estimated to be in the range of $\$ 52$ $\$ 103 / \mathrm{MWh}$, a fraction of the subsidy received (Nelson et al., 2012). To put this subsidy further into context, households at the time were charged about \$200/MWh for grid-sourced electricity. 
To compound matters, cost recovery methods for these FiT schemes were, and in some cases still $\operatorname{are}^{17}$, highly regressive in nature, since costs are recovered largely via increasing the volumetric component of the network charge.

\section{Beyond 2020 - opportunities for reform}

The broad-based increase in electricity prices since 2009 , combined with the regressive nature of the price increases, has destabilised virtually the entire electricity sector reform agenda, with increasing questions about the desirability of markets and of decentralised decision making for electricity (Quiggin, 2017). These questions reflect the combination of:

- the essential service characteristic of electricity and gas, which means consumers cannot 'exit' energy markets, especially those who cannot afford to go 'off-grid',

- similar issues arising in Great Britain, where it was argued that the increase in electricity prices from the mid-to-late 2000s was greater for financially vulnerable households compared to less vulnerable households (Littlechild, 2019), and

- a broader, macroeconomic, concern about the impacts of capitalism, 'free' markets, and globalisation, on household income and wealth inequality. These concerns have arisen in the context of declining real household incomes over the past three decades in the U.S., which is attributed to the combination of: greater offshoring and outsourcing of jobs from labour market globalisation; regressive tax-and-transfer mechanisms; and reduced bargaining power of employees via reduced collective bargaining (Kristal, 2013).

\footnotetext{
${ }^{17}$ While government-mandated FiT schemes are now closed to new applicants, the schemes remain in operation for some years yet, running to as late as June 2031 depending on the jurisdiction (ACCC, 2018).
} 
While the Hilmer-era reformists recognised the importance of well-designed redistribution schemes to facilitate the political and social acceptance, and ultimately the sustainability, of the microeconomic reform agenda, arguably more effort should have been devoted to addressing the deficiencies in redistribution mechanisms and ensuring the microeconomic reform agenda did not lead to increased (perceived or real) income inequality. Similarly, having well-designed redistribution schemes is argued to be critical to the political and social acceptance of capitalism and private sector-based market economies (Phillips 2017; Kuttner 2018).

In our view, there are demonstrated benefits from retaining a markets-led approach and decentralised decision making. The challenge is maintaining the benefits whilst addressing the legitimate concerns about the inadequacy of specific existing policies and mechanisms in the electricity sector.

Since the mid-2010s, various reforms have been introduced to address the drivers behind the runup in electricity prices. For example, time-varying (or 'cost-reflective') network prices have been introduced by some distribution network businesses, thereby reducing the chance of inefficient or excessive increases in RABs. Similarly, some of the drivers behind higher wholesale prices, such as the sudden and unexpected exit of large-scale plant, have been sought to be curbed via a requirement for generators to provide at least three years notice of closure.

However, four key reforms remain to be done. These are:

1. Lowering network prices by adopting more dynamic network pricing especially at the distribution network level, so that prices reflect the costs of supplying electricity at different times of the day. These reforms are targeted at maximising network capacity utilisation, thereby lowering prices.

2. Lowering wholesale prices by integrating emissions reduction policies with energy policies. 
3. Reforms to the ways in which generators access both transmission and distribution networks, to enable the entry of new variable renewable energy generation at the lowest cost to consumers. These reforms would enable better coordination of investment in transmission and renewable generation infrastructure, and reduce the risk of repeating the overinvestment, paid by consumers, in distribution networks that occurred during the mid-2000s.

4. Reforms to cost-recovery mechanisms, as well as reforms to redistribution mechanisms such as concession schemes, as a means of improving equity outcomes.

These reforms are particularly important because of two key disruptions now underway:

1. a change from a small number of large-scale generators to a large number of smaller, modular, renewable energy generators, and

2. millions of homes and businesses that are both electricity consumers and producers through increasing uptake of distributed energy resources (DER). The increased DER uptake is also facilitating an increasing 'digitalisation' of retail energy markets. 
It is important to note that the rationale for the reforms discussed below is that markets and facilitated decentralised decision-making remain the key means by which to promote long-term interests of customers (the 'ends'), where competition is workable and effective. In the instances where competition is unworkable, then regulation is the key means for achieving the ends. This does not mean that electricity markets should be completely unregulated (or 'free'); regulation can, should, and will play an important role in curbing market power abuse and other market failures. Instead, the preceding indicates the 'preference ranking' of tools for dealing with inefficient outcomes. Where competition is workable, inefficient outcomes should, in the first instance, be dealt with by changes to market design. Only where such a 'tool' is inappropriate or insufficient should regulatory solutions be considered. Conversely, where competition is unworkable, developing market-based solutions to address inefficient outcomes would not sufficiently deal with the issues - and may well create negative consequences of their own compared to well-designed regulatory solutions.

\subsection{Lowering distribution network prices}

As discussed in section 5.1, overestimated forecasts of peak demand were one of the drivers of the sharp increase in network prices. These overestimates, combined with the increasing "peakiness" of actual demand, have contributed to a decline in the utilisation of the existing network capacity, especially at the distribution level ( 
Figure 9).

Furthermore, capacity utilisation has consistently been lower within the government-owned distribution networks than within the privately-owned networks, even though demand is peakier in the States with privately-owned networks compared to the States with government-owned networks (

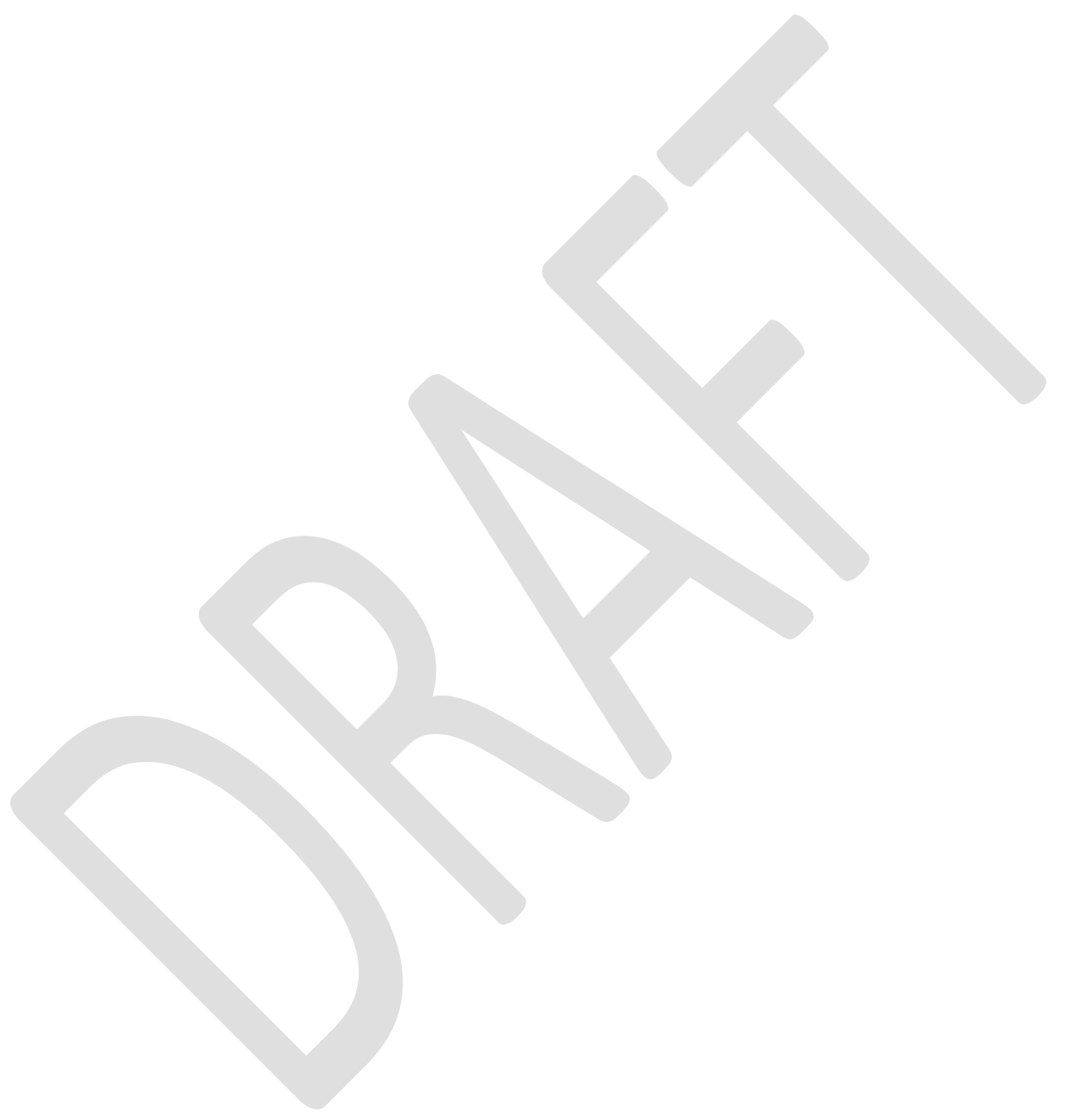


Figure 9). Hence, a key area for reform relates to boosting the utilisation of existing network capacity. Improving utilisation rates would mean a greater proportion of overall demand is served by existing capacity, lessening the need for demand-induced increases in network capacity, resulting in lower prices for all consumers.

[insert Figure 9 here]

Capacity utilisation can be increased by introducing dynamic network prices at the distribution network level, which reflect and signal the costs of supplying electricity at different times of the day. These price signals reward consumers for being able to shift their usage away from periods of network congestion (typically during periods of peak network demand), and into periods of lower network congestion. AEMC (2019) provides further more details on this proposed reform.

A further option for reducing network prices is relieving customers of the cost of financing network investments that appear stranded from excessively tight reliability standards and/or overestimated demand forecasts. Some argue taxpayers in the relevant States should finance this apparent overhang (Simshauser and Akimov, 2019); others argue these assets should be written off (ACCC, 2018). ${ }^{18}$ Either approach could have negative implications for new investment, however, by driving up the risk premium and cost of capital for new investments in transmission and distribution infrastructure.

\subsection{Integrated energy and climate policy}

The lack of a nationally consistent long-term mechanism to reduce emissions in the electricity industry needs to be addressed in a way that links financial incentives to the physical needs of the system. ${ }^{19}$ Investments made to reduce emissions in the electricity industry need to be driven by financial incentives to provide energy services at times when consumers and the power system need them. Technology non-neutrality has been created by production subsidies such as the RET,

${ }^{18}$ A third option for improving network capacity utilisation, and in turn lowering network prices, is the load-shedding compensation mechanism proposed by Walker, Falvi and Nelson (2019). This mechanism could make demand becomes more price-responsive, thereby limiting the need for additional generation and network investment.

${ }^{19}$ It is worth noting that while the discussion in this section relates to electricity sector-specific emissions reduction mechanisms, the preferred approach remains an economy-wide mechanism, as argued in Nelson et al. (2019) 
which have been designed solely for emissions reductions and subsidise specific forms of generation instead of directly pricing the externality.

Currently investors are unsure about how to calculate their future risks and revenues, particularly in relations to emissions. In addition, the profitability of generation technologies varies across alternative future emissions reduction scenarios. This is especially true for gas-fired plant and other relatively low carbon-emitting plant whose expected returns diminish as emissions reduction targets increase (AEMC, 2016). ${ }^{20}$

Uncertainty about emissions reduction policies creates barriers to entry for new "dispatchable" plant. To overcome this barrier, an emissions policy mechanism is needed that:

- guides investors on what investments to make such that future costs, risks and revenues under alternative future scenarios can be calculated with a higher degree of certainty, and is designed to meet the physical needs of the power system through alignment of the financial incentives of market participants. Market participants need to remain incentivised to positively correlate their output with demand by responding to wholesale price signals, rather than just generating at any time of day regardless of whether or not the system needs that generation at that time or not, and

- achieves the emissions reduction targets set by government.

An emissions trading scheme (either an absolute or an intensity-based scheme) would achieve these objectives. Such a mechanism could be used to meet an independently-set emissions trajectory at Commonwealth and/or State government level.

\subsection{Enabling generators to finance network investment}

In those parts of Australia covered by the NEM, often the best wind and solar resources are located in areas with relatively low amounts of existing transmission network capacity.

${ }^{20}$ In contrast, as coal-fired plants have higher emissions intensities, this makes them less economically viable in virtually all carbon-constrained scenarios. This makes coal a less uncertain proposition from private investors' perspectives i.e. coal is virtually certain to generate insufficient investor returns in every future state of the world. 
Furthermore, these locations are typically quite some distance from existing loads and often more remotely located than existing thermal generators. As noted in previous sections, the penetration of variable renewables has surged since 2017, with almost 4,700 MW of wind and solar PV capacity entering the NEM in 2017 and 2018, with a further 2,600 MW expected to enter in 2019 and 2020 (see Figure 4). This may depress the revenues and profits of existing and new-entrant variable renewables in the following three ways:

1. Correlation-induced impacts. As wind and solar PV generators have entered a region (with South Australia having had the highest penetration of variable renewables), they have located in areas with the best geography. Over time this has resulted in an increasing correlation of output between wind, and between solar PV. This higher "correlation penalty" reduces the prices received by these generators (Hirth, 2013). ${ }^{21}$

2. Congestion-induced impacts. The correlation between generators has been further increased by new-entrants co-locating with incumbents. This increase in coincident output has, at times, exceeded the (modest) capacity of the transmission network - as noted above - resulting in increasing instances of output being 'spilled'.

3. Higher electrical losses (i.e. lower marginal loss factors, MLFs). Those generators that locate in areas away from major load centres incur losses associated with the transport of electricity to those load centres. For some generators, these losses have increased over time due to increasing generator co-location. Between 2018/19 and 2019/20, wind and solar PV generators typically experienced the largest decrease in MLFs, of up to 23 per cent (AEMO, 2019). This translates into a 23 per cent decrease in generator revenues. Dynamic regional pricing is one way of providing an efficient signal to generators in relation to the costs of congestion, and in turn the benefits of alleviating that congestion by either: adding to network capacity, changing generation patterns, and/or locating in a different part of the network.

\footnotetext{
${ }^{21}$ For example, dispatch-weighted prices received by South Australian wind generators over the year to 30 June 2018 were around 25 per cent lower than time-weighted prices.
} 
By incentivising generators to invest and operate in places with higher levels of existing transmission capacity, electricity demand can be met by the lowest-cost mix of generation. Such a reform is important to ensure market participants, not electricity customers, bear the risk of new investment. This philosophical approach to risk allocation underpinned the original intent of the NEM reforms of the 1990s (see section 4).

\subsection{Making price rises less regressive}

Reforms are needed to the recovery of transmission and distribution network costs, as a higher percentage of these costs are recovered via volumetric charges than via fixed charges. This allocates more the costs of networks to consumers who are unable to reduce their grid-sourced electricity. Financially vulnerable households are less able to afford measures such as rooftop PV systems and batteries that reduce grid-sourced electricity consumption, meaning they are paying an increasing share of network costs.

Cost recovery mechanisms for government subsidies also require reform. Government subsidies, such as those to increase the amount of rooftop PV, have been highly regressive in nature, increasing the share of network costs being paid by the more financially vulnerable, as the cost of the schemes have been largely recovered via increased distribution network charges.

Finally, government concession schemes need to be reformed as existing schemes are not welltargeted to those most in need, and are not harmonised across jurisdictions, causing a lack of knowledge about their existence (Simshauser and Nelson, 2014).

\subsection{Concluding remarks}

As we have outlined, the NEM was built around the key economic principles of competition and risk allocation. From the late 2000 s, governments have strayed from these principles by intervening in ways that disempowered consumers and markets - such as through the implementation of poorly-designed emissions reduction and cost recovery mechanisms. Given the 
disruptions underway in the electricity sector, it is more important than ever that the electricity

sector adheres to the principles underpinning the NEM. Our reform recommendations do this.

\section{References}

ACCC, 2018. Restoring electricity affordability and Australia's competitive advantage, Retail electricity pricing inquiry - final report, June, Australian Competition and Consumer Commission, Canberra.

AEMC, 2019. Integrating distributed energy resources for the grid of the future: Economic regulatory framework review, 26 September, Australian Energy Market Commission, Sydney.

AEMC, 2018. 2018 Residential electricity price trends, 18 December, Australian Energy Market Commission, Sydney.

AEMC, 2017. Strategic priorities for the Australian energy sector, discussion paper, 12 September, Australian Energy Market Commission, Sydney.

AEMC, 2016. Integration of energy and emissions reduction policy, report, 09 December, Australian Energy Market Commission, Sydney.

AEMO, 2019. Regional boundaries and marginal loss factors for the 2019-20 financial year, 21 June, Australian Energy Market Operator, Melbourne.

AER, 2018a. Annual report on compliance and performance of the retail energy market 2017-18, 13 December, Australian Energy Regulator, Melbourne.

AER, 2018b. Wholesale electricity market performance report, 11 December, Australian Energy Regulator, Melbourne.

Booth, R., 2000. Warring tribes: the story of power development in Australia, Bardak Group.

Brady, F., 1997. A dictionary on electricity, a report prepared for the Australian National Committee of The International Conference on Large High Voltage Electrical Systems (CIGRE) and The Association for the History of Electricity in France (AHEF), Sydney.

CER, 2018. When does the Renewable Energy Target end?, 31 May, Clean Energy Regulator, Canberra.

Chester, L., 2006. The conundrums facing Australia's national electricity market, Economic Papers, 25(4), pp. 362-77.

Hirth, L., 2013. The market value of variable renewables, Energy Economics, 38, pp. 218-236.

Industry Commission, 1991. Energy generation and distribution, inquiry report, Canberra.

Kristal, T., 2013. The capitalist machine: computerization, workers' power, and the decline in labor's share within U.S. industries, American Sociological Review, 78(3), pp. 361-389. 
Kuttner, R., 2018. Can democracy survive global capitalism?, W. W. Norton.

Littlechild, S., 2019. Promoting competition and protecting customers? Regulation of the GB retail energy market 2008-2016, Journal of Regulatory Economics, 55(2), pp. 107-139.

Meagher, G., Adams, P., and Pang, F., 2014. Climate change mitigation, economic growth and the distribution of income, Working paper, Centre of Policy Studies/IMPACT Centre.

Mountain, B., and Littlechild, S., 2010. Comparing electricity distribution network revenues and costs in New South Wales, Great Britain and Victoria, Energy Policy, 38(10), pp. 5770-82.

Nelson, T., Pascoe, O., Calais, P., Mitchell, L., and McNeill, J., 2019. Efficient integration of climate and energy policy in Australia's National Electricity Market, Economic Analysis and Policy , 64, pp. 178-193.

Nelson, T., Bashir, S., McCracken-Hewson, E., and Pierce, M., 2017. The changing nature of the Australian electricity industry, Economic Papers, 36(2), pp. 104-120.

Nelson, T., Simshauser, P., and Nelson, J., 2012. Queensland solar feed-in tariffs and the meritorder effect: economic benefit, or regressive taxation and wealth transfers?, Economic Analysis \& Policy, 42(3), pp. 277-301.

Nelson, T., Kelley, S., Orton, F., and Simshauser, P., 2010. Delayed carbon policy certainty and electricity prices in Australia, Economic Papers, 29(4), pp. 446-465

Phillips, N., 2017. Power and inequality in the global political economy, International Affairs, 93(2), pp. 429-444.

Pollitt, M. 2004, "Electricity reform in Chile: lessons for developing countries", Working paper 04-016, CEEPR, University of Cambridge.

Queensland Government, 2017. Powering Queensland plan: an integrated energy strategy for the State, Department of Energy and Water Supply, June.

Queensland Government, 2007. Queensland gas scheme proves a winner, Minister for Mines and Energy, 03 April.

Quiggin, J., 2017. The case for renationalising Australia's electricity grid, 06 March, The Conversation.

Reinhardt, S., and Steel, L., 2006. A brief history of Australia's tax system, Economic Roundup, Commonwealth Treasury, Canberra.

Simshauser, P., 2019. The strengths and weaknesses of Australia's national electricity market, article in press.

Simshauser, P., 2016. Distribution network prices and solar PV: resolving rate instability and wealth transfers through demand tariffs, Energy Economics, 54(3), pp. 108-122.

Simshauser, P., 2014. From first place to last: the national electricity Market's policy-induced 'energy market death spiral', Australian Economic Review, 47(4), pp. 540-562.

Simshauser, P., and Akimov, A., 2019. Regulated electricity networks, investment mistakes in retrospect and stranded assets under uncertainty, Energy Economics, 81, pp. 117-133.

Simshauser, P., and Downer, D., 2016. On the inequity of flat-rate electricity tariffs, Energy Journal, 37(3), pp. 199-229.

Simshauser, P., and Nelson, T., 2014. The consequences of retail electricity price rises: rethinking customer hardship, The Australian Economic Review, 47(1), pp. 13-43.

Simshauser, P., and Nelson, T., 2013. The outlook for residential electricity prices in Australia's national electricity market in 2020, The Electricity Journal, 26(4), pp. 66-83. 
Simshauser, P., and Whish-Wilson, P., 2017. Price discrimination in Australia's retail electricity markets: an analysis of Victoria \& Southeast Queensland, Energy Economics, 62, pp. 92-103.

Sood, R., 2014. Time for solar to pay its way: should we restructure network tariffs?, briefing note, March, Frontier Economics Pty Ltd, Melbourne.

Walker, T., S. Falvi, and T. Nelson, 2019. A new approach to valuing reliability in Australia's national electricity market, IAEE Energy Forum, pp. 27-29. 
Figure 1: Installed generation capacity across Australia (1955 - 1997)

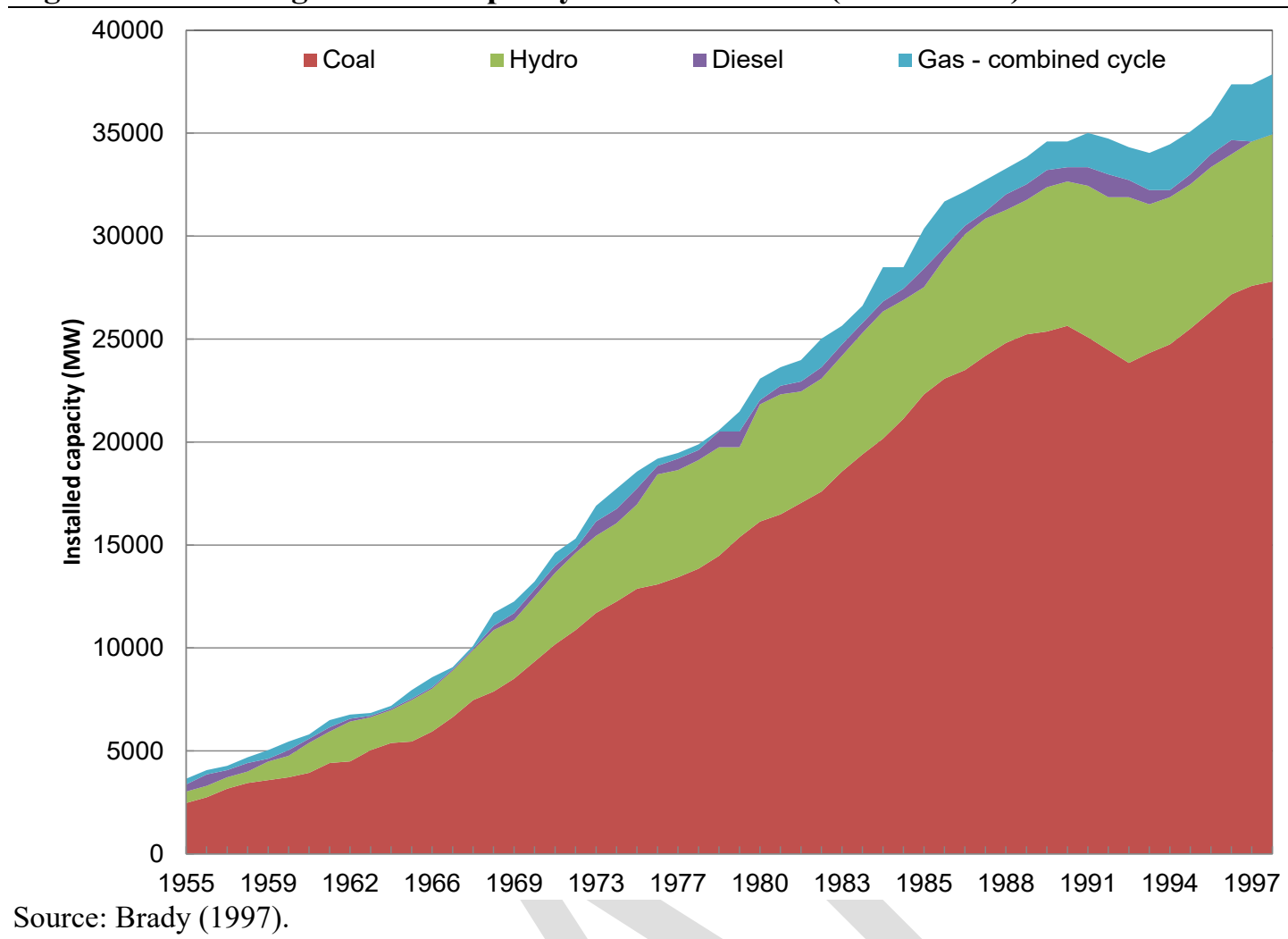

Figure 2: Residential electricity prices in NSW and Queensland (1955 - 2018)

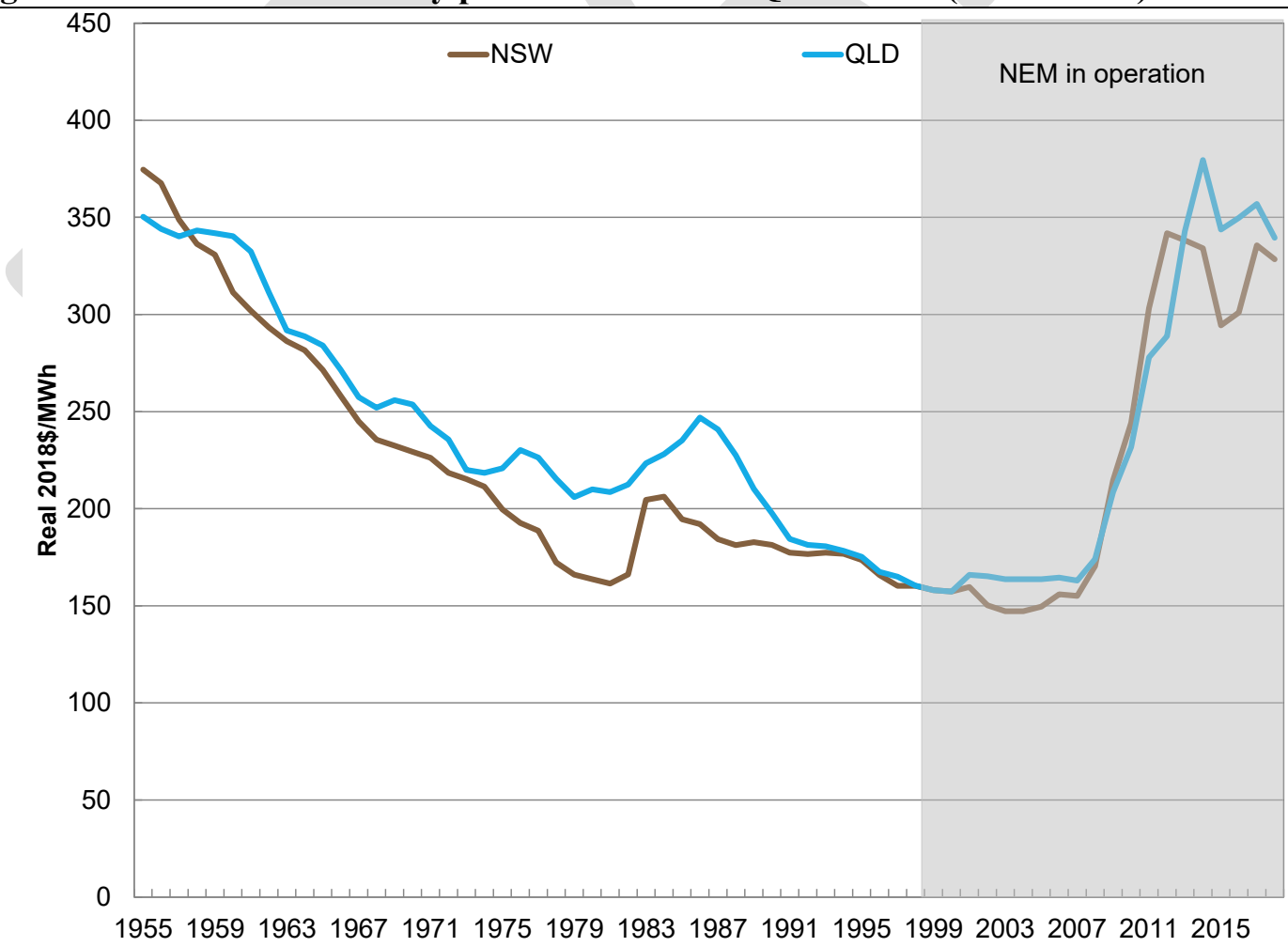

Notes: Shaded area indicates period over which the NEM has been in operation.

Sources: AEMC (2018); Nelson et al. (2017); Simshauser (2019); St. Vincent de Paul \& Alviss Consulting. 
Figure 3: Wholesale spot electricity prices in the NEM (1999-2018)

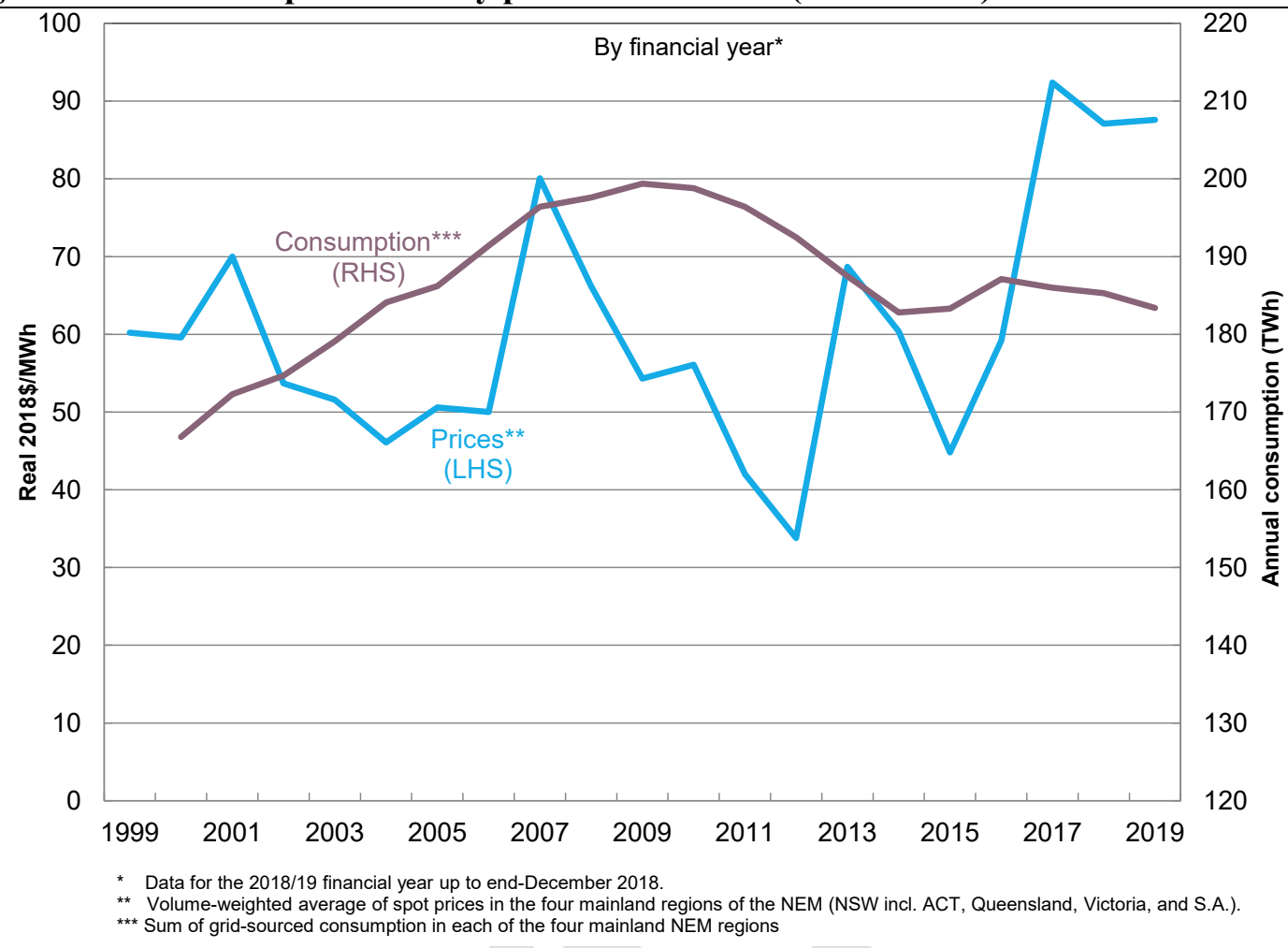

Source: Authors' analysis of AER data.

Figure 4: Entry and exit of generation capacity in the NEM (1999-2018)

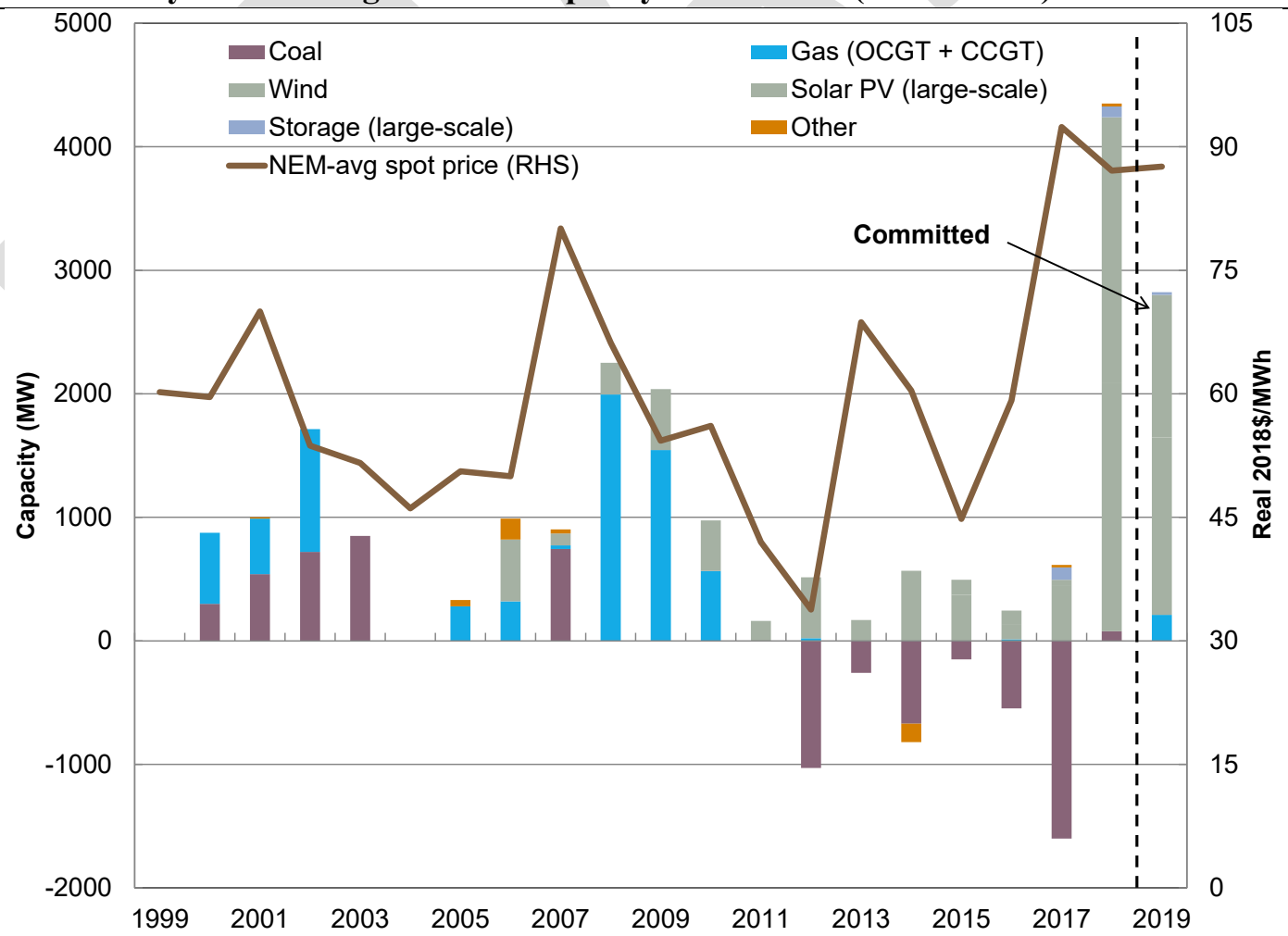

Source: Authors' analysis of AER, AEMO, and ESAA data. 
Figure 5: Drivers of higher residential electricity prices across the NEM (2008 - 2018)

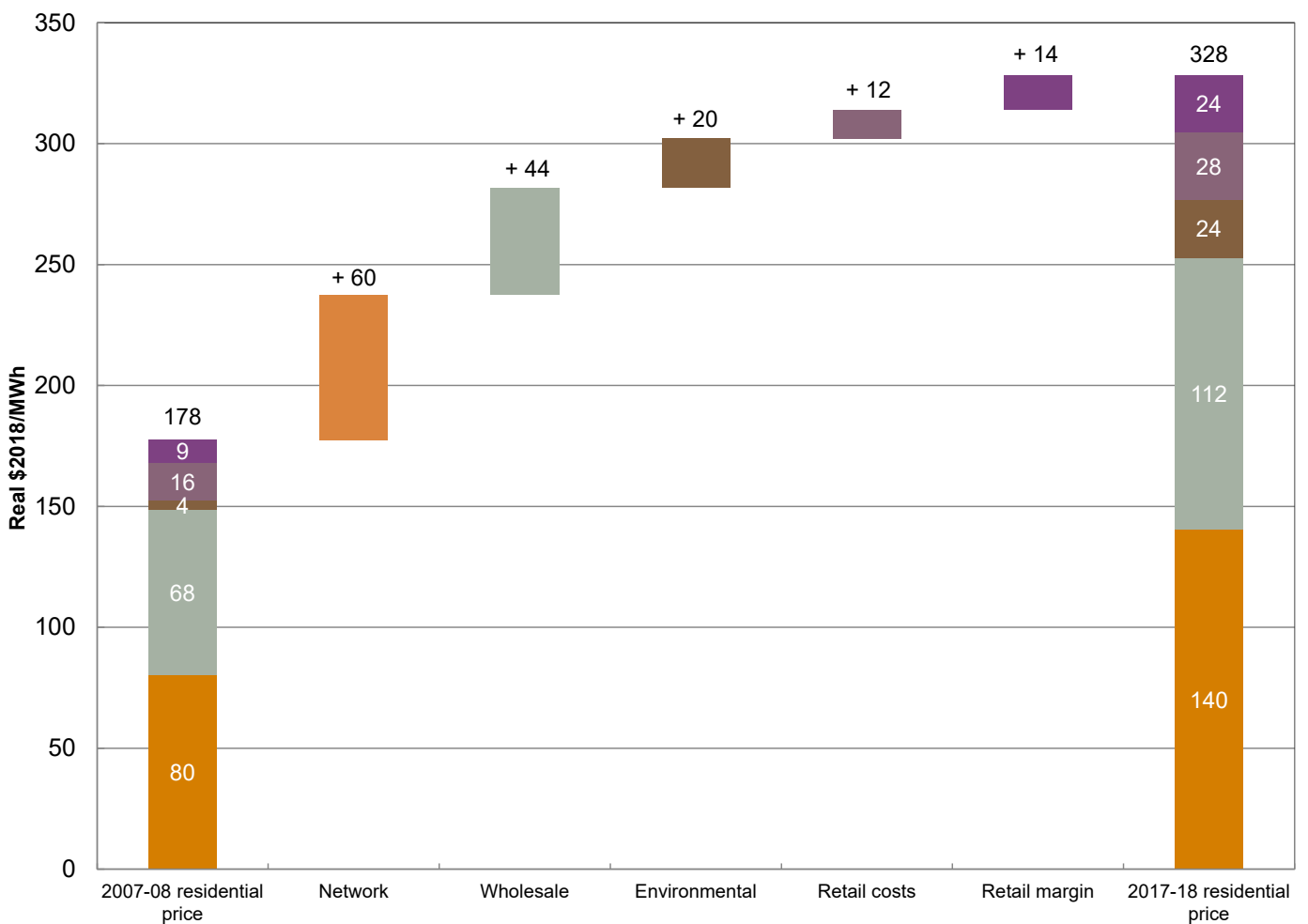

Source: Authors' analysis of data from ACCC (2018) and St. Vincent de Paul \& Alviss Consulting.

Figure 6: Distribution network revenues, RABs and network prices (2006 - 2017)

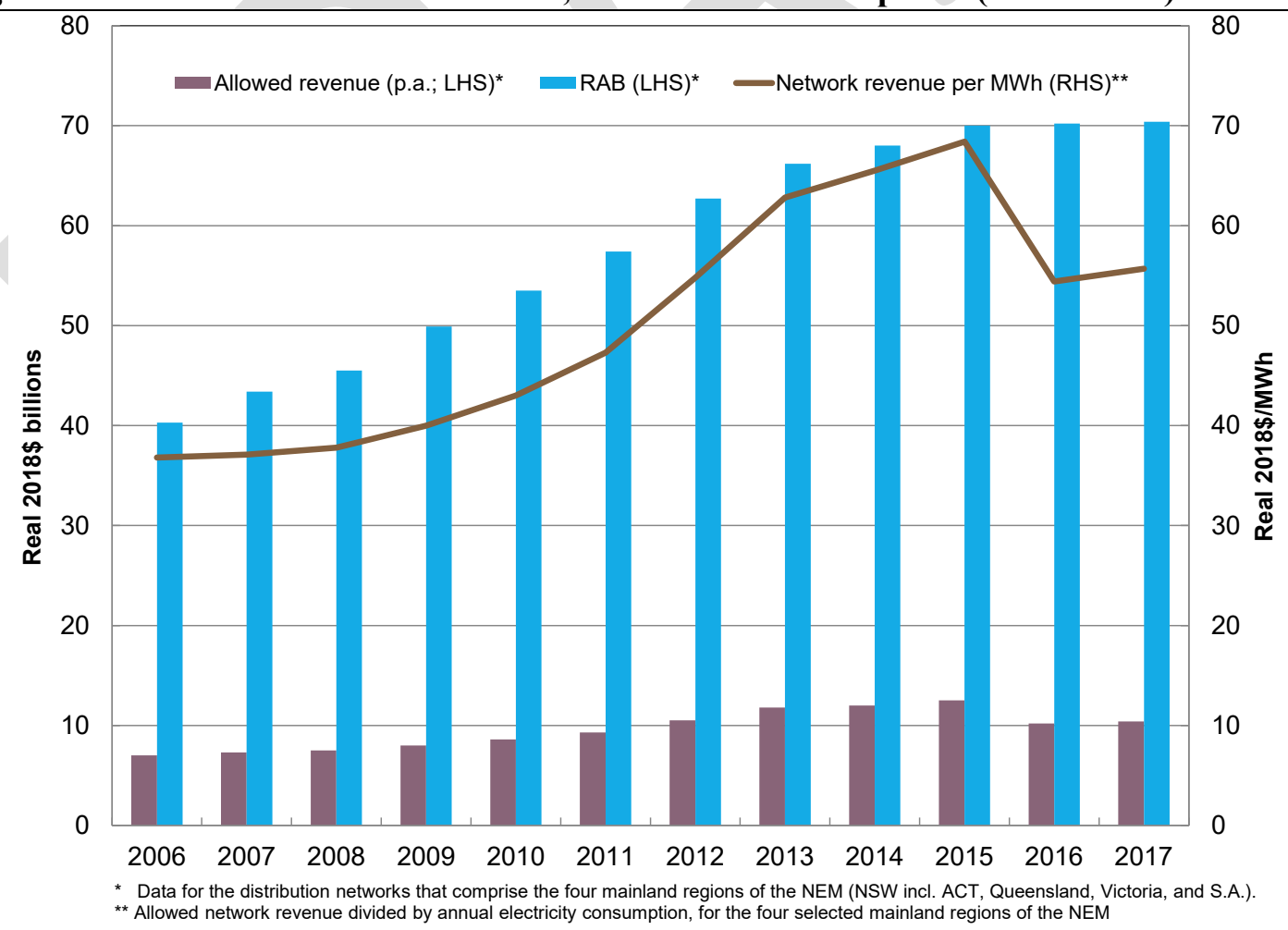

Source: Authors' analysis of AER data 
Figure 7: Gas prices, coal prices, and NEM-wide electricity prices (2009 - 2018)

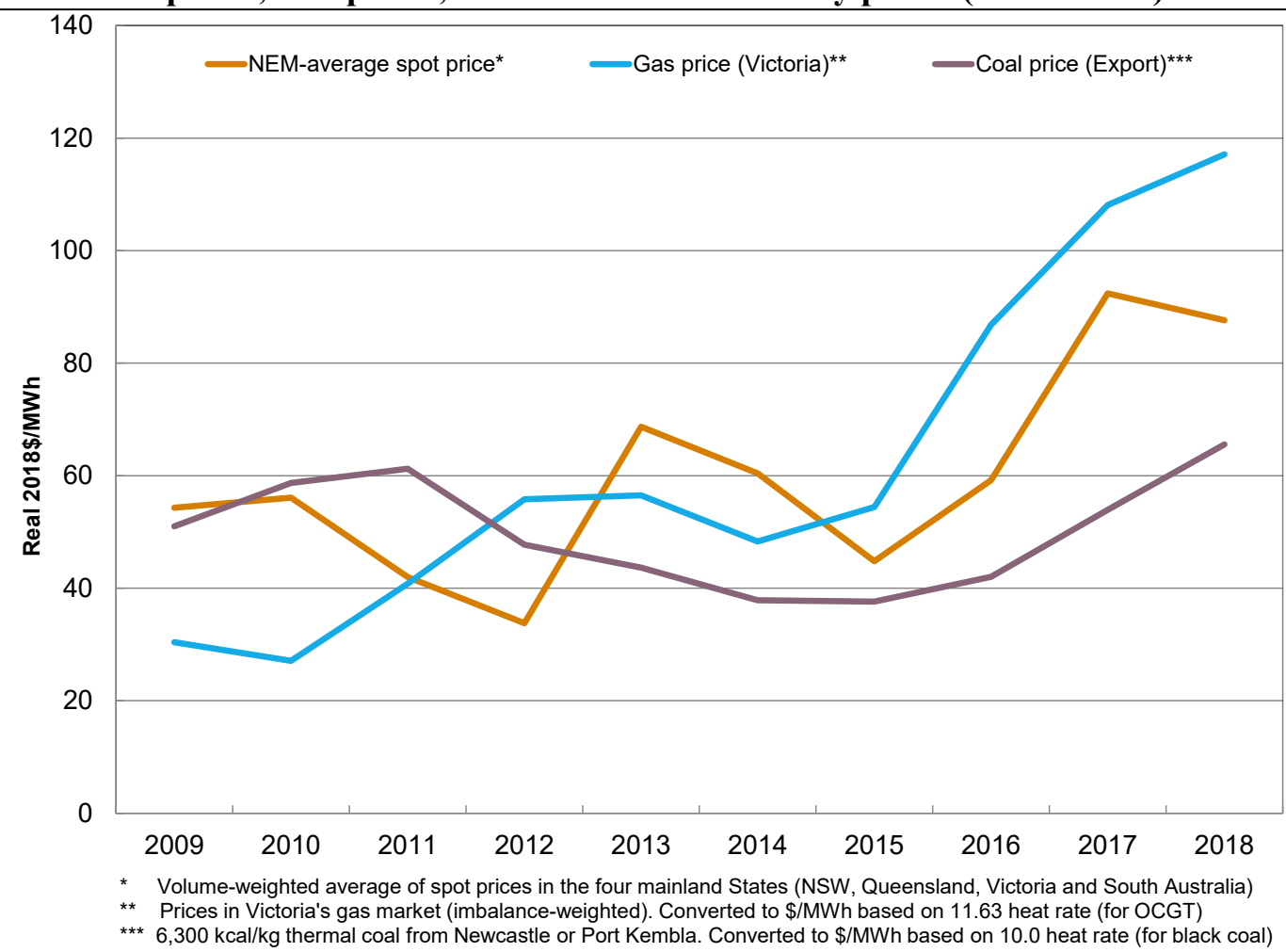

Source: Authors' analysis of data from the AER and from indexmundi

Figure 8: Household expenditure on electricity by household-income segment, NEM-wide

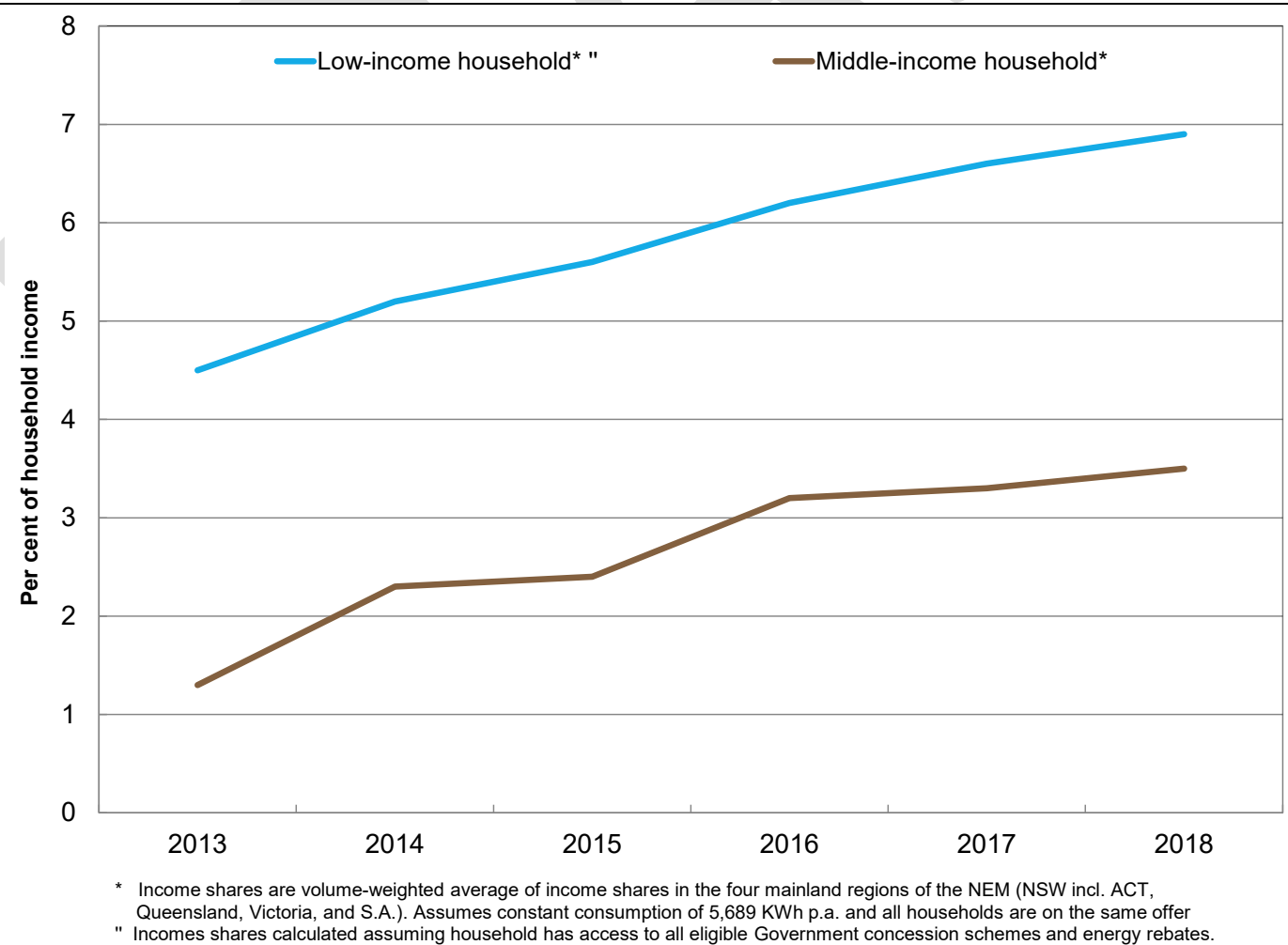

Source: Authors' analysis of AER data 
Figure 9: Peakiness of demand and distribution network capacity utilisation

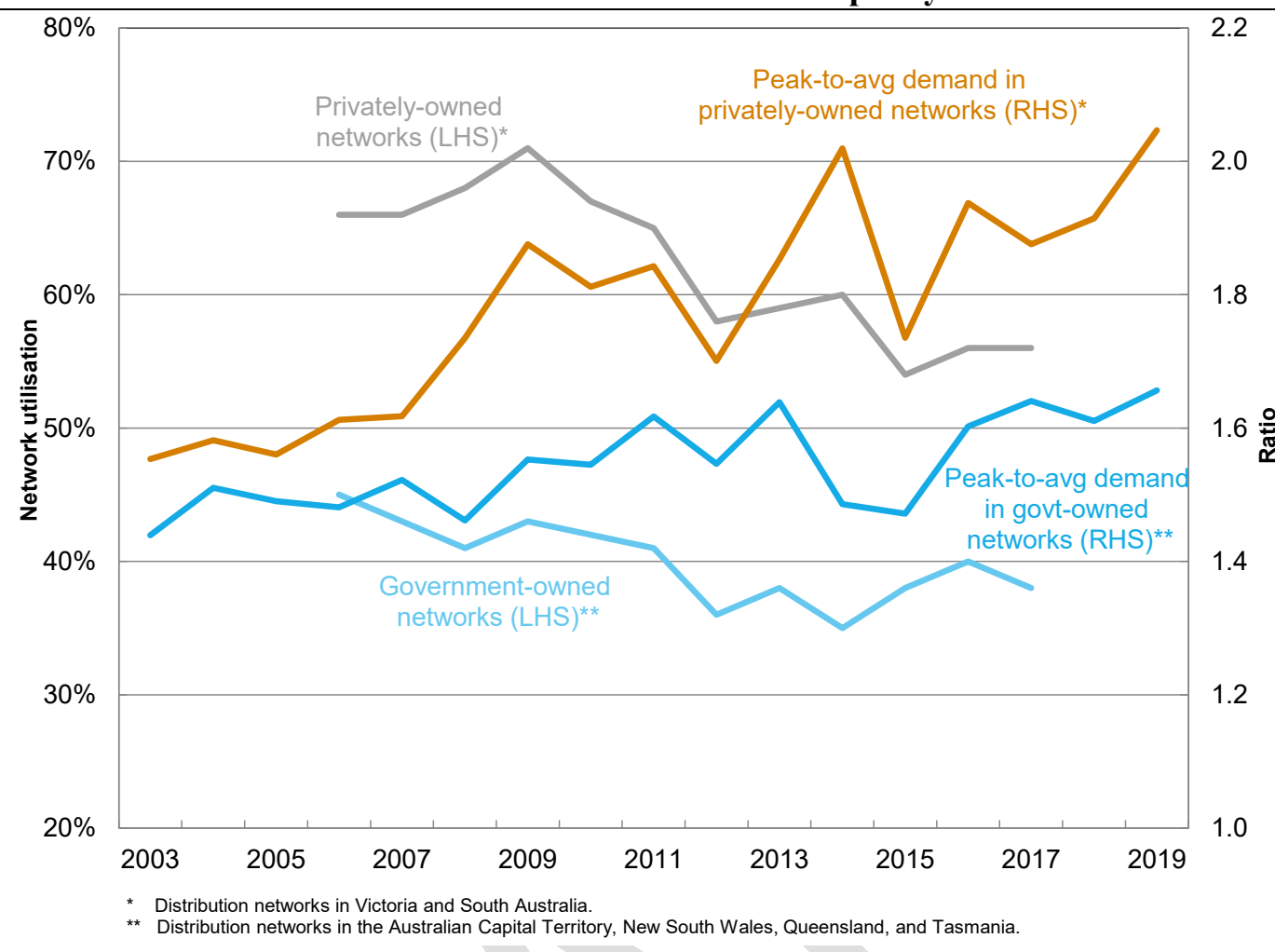

Source: Authors' analysis of AER and AEMO data 